\title{
26 Research Suare \\ Experimental design of a culture approach for corneal endothelial cells
}

\section{Maria Dolores Montalvo-Parra}

Instituto Tecnologico y de Estudios Superiores de Monterrey https://orcid.org/0000-0002-4789-5134

\section{Isaac Alejandro Vidal-Paredes}

Instituto Tecnologico y de Estudios Superiores de Monterrey

\section{Cesar E. Calzada-Rodriguez}

Instituto Tecnologico y de Estudios Superiores de Monterrey

Italia Tatnaí Cárdenas-Rodríguez

Instituto Tecnologico y de Estudios Superiores de Monterrey

Guiomar Farid Torres Guerrero

Instituto Tecnologico y de Estudios Superiores de Monterrey

Daniela Gomez Elizondo

Instituto Tecnologico y de Estudios Superiores de Monterrey

Mariana Lopez Martínez

Instituto Tecnologico y de Estudios Superiores de Monterrey

Judith Zavala ( $\square$ judith.zavala@tec.mx )

Jorge E. Valdez-García

Instituto Tecnologico y de Estudios Superiores de Monterrey

\section{Research}

Keywords: Corneal endothelium, ATPase, Collagen, Circularity, Experimental design, Cell culture

Posted Date: April 30th, 2020

DOI: https://doi.org/10.21203/rs.3.rs-25005/v1

License: (9) (i) This work is licensed under a Creative Commons Attribution 4.0 International License. Read Full License 


\section{Abstract \\ Background}

The harvesting of corneal endothelial cells (CECs) has received special attention given its potential as therapy for corneal blindness. The main challenges to overcome for this purpose are related to the culture media formulation, cellular density at the primary isolation, and the number of passages in which CECs can retain their functional characteristics. The alternance of different media formulations to harvest CECs has an impact on the cellular yield and morphology. We herein analyzed eight different sequences of growth factor-supplemented proliferative $(P)$ and non-supplemented resting $(R)$ media upon passages to find the optimal $P / R$ culture media sequence in regards of cell yield, morphology, procollagen I production, ATPase function, and the expression of ZO-1 and ATPase.

\section{Results}

PRPR and PRRR sequences showed the higher cell yield and hexagonal morphology rate. CECs cultured in the PRRR sequence produced procollagen I, showed Na/K-ATPase function, and expression of ZO-1 and $\mathrm{Na} / \mathrm{K}$-ATPase by immunocytochemistry. Our study sets a culture approach to guarantee CECs expansion, as well as functionality for their potential use in tissue engineering and in vivo analyses.

\section{Conclusions}

Alternation of $\mathrm{P}$ and $\mathrm{R}$ culture media improves CECs culture. PRRR sequence demonstrated to be effective and for CECs proliferation lowering the cost implied in PRPR sequences. We discarded the use of pituitary extract and ROCK inhibitors as essential for CECs proliferation.

\section{Background}

Corneal endothelial cells (CECs) are the cells of the inner layer of the cornea that functions as a barrier and pump for the maintenance of the optimal hydration level for the eye to perform its vision function [1, 2]. The clarity and nutrition of the cornea rely on these functions, given that it is an avascular tissue [3]. The damage to the corneal endothelium can lead to blindness because CECs are arrested in the $\mathrm{G}_{1}$ cell cycle phase[4-6]. Corneal blindness can only be treated through transplantation, however, this procedure faces the shortage of tissue donors $[3,7-10]$.

The expansion of CECs through culture has received special attention among the efforts to develop an alternative to donor tissue. Several experimental approaches aim to develop a method to isolate and harvest CECs for corneal blindness cell therapy and tissue engineering $[3,11]$.

For these purposes, challenges such as culture media[12-16] formulation cellular density [17], and number of passages that assures functionality $[16,18]$ need to be overcome. The factors that affect the 
overall yield of CECs are donor-to-donor variation and the use of different serum-supplemented culture media[19, 20]. Although a robust and clearly described culture methodology is still lacking, a great amount of clinical interest has been generated for the development of alternative approaches in the treatment for corneal endothelium damage-associated corneal blindness using cultured CECs.

We previously reported a two-phase CECs culture system that allows cellular expansion and retains specific molecular markers, hexagonal morphology and monolayer arrangement [21]. Now, in order to set the best culture media combination, we aimed to analyze the CECs obtained from different approaches in terms of cell yield, morphological analysis, pro-collagen production, ATPase function, and the expression of ZO-1 and ATPase.

\section{Methods}

\section{Experimental Design}

A two-phase culture system was established to be used in CECs culture. Two-phase refers to the alternation of two media of different compositions: Proliferative $(P)$ and resting $(R)$ media. Our modified formula [21] of previously reported P media [14] contained Opti-MEM I (Gibco®; Thermo Fisher Scientific, Waltham, MA) supplemented with $8 \%$ fetal bovine serum (FBS; Cellgro, Manassas, VA) and $1 \%$ penicillin/streptomycin (Pen/Strep; Thermo Fisher Scientific), $20 \mathrm{ng} / \mathrm{ml}$ of nerve growth factor (NGF; Sigma-Aldrich Co.), $5 \mathrm{ng} / \mathrm{ml}$ of epidermal growth factor (EGF; Sigma-Aldrich Co.), $200 \mathrm{mg} / \mathrm{l}$ of calcium chloride (Sigma-Aldrich Co.), $20 \mu \mathrm{g} / \mathrm{ml}$ of ascorbic acid (Sigma-Aldrich Co.), $0.08 \%$ chondroitin sulfate (Sigma-Aldrich Co.). R media formulation was Opti-MEM I supplemented with 8\% FBS and 1\% Pen/Strep. Experimental design consisted of alternating media through several passages to evaluate combinations of the phases of our culture system as shown in Fig. 1. Eight sequences of alternating media were evaluated. The objective was to produce a maximum cell yield while conserving CECs characteristics.

Passage 0 consisted in recently isolated CECs cultured in a 12-well plate with $\mathrm{P}$ media until hexagonal morphology was observed (confluence beyond 80\%). All passages herein mentioned followed a hexagonal morphology and $>80 \%$ confluence rule. At passage 1, CECs were splitted 1:2 and the medium was changed using R media. The culture continued up to passage 3. An Axiovert $40 \mathrm{CFL}$ contrast microscope (CFL; Carl Zeiss AG, Oberkochen, Germany) featuring a PowerShot A640 digital camera (Canon Inc., Tokyo, Japan) was used to register the cell morphology.

\section{Isolation And Culture Of CEC}

This study was approved by the Institutional Ethics Committee (School of Medicine of Tecnologico de Monterrey), number 2017-005. All animals were treated according to the Guide for the Care and Use of Laboratory Animals. 
The corneas were obtained from four 3-month-old New Zealand rabbits weighing $\sim 3 \mathrm{~kg}$. The rabbits were euthanized under general anesthesia with a combination of xylazine $5 \mathrm{mg} / \mathrm{kg}$ and $30 \mathrm{mg} / \mathrm{kg}$ of ketamine [WU2] (Pisa Farmaceutica, Guadalajara, México); followed by a lethal intraperitoneal injection of sodic pentobarbital (Pets Pharma, Estado de Mexico, Mexico). The corneas were excised, rinsed with $37^{\circ} \mathrm{C}$ Phosphate Buffered Saline (PBS) pH 7.4 (Gibco, Thermo Fisher Scientific, Waltham, MA) with 1\% streptomycin/penicillin antibiotics (Thermo Fisher Scientific), and placed in a sterile tissue culture dish.

All rabbit CECs were isolated using the "peel-and-digest" approach. Excised whole corneas were placed in a petri dish with PBS, all inside the Biosafety cabinet. Then, Trypan blue $(0.04 \%$, Milipore Sigma, Merck $\mathrm{KGaA}$, Darmstadt, Germany) was poured on the endothelial side of the cornea for 1 min to stain CE borders. Trypan blue was then rinsed using PBS. The border of CE was gently pushed around the whole circumference. Descemet's membrane with the intact endothelium (DM/CE) was carefully peeled from the corneal stroma and rinsed several times with $37^{\circ} \mathrm{C}$ PBS with $1 \%$ antibiotics. DM/CE complexes were incubated in Opti-MEM I 8\% FBS and the 1\% antibiotic combination overnight to stabilize the cells before culture. CE were incubated, while shaking at $170, r p m$ with $1 \mathrm{mg} / \mathrm{ml}$ of collagenase type I (Sigma-Aldrich Co., St. Louis, MO) at $37^{\circ} \mathrm{C}$ for $1 \mathrm{~h}$. Cells were collected following centrifugation at $375 \times \mathrm{g}$ for $10 \mathrm{~min}$ and seeded into a 12-well culture dish.

\section{Cell Yield Analysis}

Cell yield was calculated to produce evidence of morphology changes when cells were continuously cultured in $\mathrm{P}$ media and when cultured occurred in alternation with $\mathrm{R}$ media. For this analysis, the quotient of cellular concentration (cells $/ \mathrm{ml}$ ) at the end of passage 2 divided by the cellular concentration at the end of passage 1 was calculated for each media sequence. The average and the standard error were calculated. A $t$ test was used to analyze statistically significant differences between the calculated yields.

\section{Morphological Analysis}

CECs were observed (Axioivert 40CFL inverted microscope, Zeizz, Germany) and photo documented daily. Scale was set on each photograph and 40 cells per daily image were delimited with free shape ROI tool from Image J. Perimeter $(P)$, area $(A)$, circularity $(C)$, aspect radio $(A R)$ and roundness $(R)$ indexes were obtained using Measure (Analyze menu). Basal parameters were also measured from cells observed in pictures obtained from recently isolated Descemet's membrane. Statistical analysis was performed through a one-way ANOVA complemented with an all pairwise multiple comparison procedure by HolmSidak method $(P=0.001)$. Microsoft Excel $(2007$, Redmond, WA) was used for data processing. Statistical analysis and graph creation were carried out using Systat Sigma Plot (V. 11, San Jose, CA).

\section{Protein Production Analysis}


Cultured cells were detached using trypsin and then and centrifuged at $500 \times \mathrm{g}$ for 5 min at $4{ }^{\circ} \mathrm{C}$ to obtain a cell lysate for total protein analysis. The pellet was washed three times with $1 \mathrm{X}$ PBS buffer and incubated 20 min with extraction buffer (Abcam ab193970) on ice. The solution was centrifuged at $18,000 \mathrm{x} \mathrm{g}$ for 20 minutes at $4^{\circ} \mathrm{C}$. The supernatant was used for the total protein concentration analysis. Colorimetric bicinchoninic acid assay (BCA Pierce 23225) was used. A standard curve was prepared using albumin provided in the kit. The concentration of total protein was measured at $562 \mathrm{~nm}$ in a spectrophotometer. The assay was done in triplicates using a dermal fibroblast cell line as control. Statistical analysis was performed with a $t$-test using Microsoft Excel (2007, Redmond, WA).

\section{Procollagen I Alpha 1 Analysis}

Pro-collagen I-a1 was determined as a measure of the ability of the cells to produce collagen 1-a1, ELISA Kit (Abcam ab210966) was used with the cell lysates described before. The procedure was followed in accordance with the kit manufacturer and the absorbance was measured at $562 \mathrm{~nm}$ in a microplate reader. The assay was done in triplicates using a dermal fibroblast cell line as control. Statistical analysis was performed with a $t$-test using Microsoft Excel (2007, Redmond, WA).

\section{Biomarker Immunodetection (Z01 And ATPase)}

Immunocytochemistry was performed on basal whole cornea and on CECs passage 2 cultured with PRR media sequence combination to analyze the presence ZO-1 (Thermo Fisher, 61-7300, Waltham, MA), and $\mathrm{Na}$ /K-ATPase (Abcam, ab176163, Cambridge, UK). The procedure consisted of overnight cell stabilization over coverslips with poly-D lysine (Sigma-Aldrich, P7280), fixation with 4\% paraformaldehyde, nonspecific bonding blockage with $5 \%$ bovine serum albumin (BSA; Sigma-Aldrich, A-7030), overnight $4{ }^{\circ} \mathrm{C}$ incubation with primary antibodies (ZO-1 $5 \mu \mathrm{g} / \mathrm{ml}$ and $\mathrm{Na} / \mathrm{K}$-ATPase 1:100), and incubation with Alexa Fluor 488 secondary antibody (Abcam, ab150077) for $1 \mathrm{~h}$ at room temperature. Fluroshield Mounting Medium with 4',6-Diamidino-2'-phenylindole dihydrochloride (DAPl; Abcam, ab104139) counterstain was used. Epifluorescence was registered with a widefield fluorescence microscope (Zeiss Imager Z1) with an AxioCam HRm (Zeiss) camera (Göttingen, Germany). Whole width cornea sections were used as controls [15].

\section{ATPase Activity Analysis}

A colorimetric enzymatic assay was used to measure the ATPase activity (Mybiosource MBS8243226). Cells (CEC and dermal fibroblasts) were harvested when confluence was reached and sonicated for the detection in accordance with the manufacturer procedure. The final absorbance was registered at $660 \mathrm{~nm}$. The assay was done in triplicates using a dermal fibroblast cell line as control. Statistical analysis was performed with a $t$-test using Microsoft Excel (2007, Redmond, WA). 


\section{Results}

\section{Cell yield}

Cell yield analysis was carried out to select the media sequence with higher yield (Table 1). The expansion folds were calculated for the sequences with the higher cell concentration at the end of passage 3. Briefly, sequence 1 produced a 12 -fold, sequence 2 a 6.5 -fold, sequence 3 a 4.6 -fold, and sequence 4 produced a 7.5-fold expansion. Time to confluence varied for the different media sequences as shown in Fig. 2. Moreover, differences in the time to reach confluence were observed on the same sequence as seen for combinations 4-7.

Table 1

Media sequence selection based on cellular expansion yield. Higher cell yields were reached with sequences 1-7. Cellular size was observed to be smaller at higher yields. Selection of optimum sequence also considered morphology. Thus, sequence 4 (PRRR) was selected. Expansion yield was calculated for each media sequence as the average of the difference between the initial seeded cells and the final cellular concentration when trypsinized for each passage. Cell counts were performed with a Neubauer chamber by duplicate. Results were compared with one way ANOVA $(p=0.001)$. Proliferative media $(P)$; resting media $(R)$.

\begin{tabular}{|c|c|c|c|c|c|c|}
\hline \multicolumn{7}{|c|}{ Cell concentration (cell number $\times 10^{3}$ ) $/ \mathrm{mm}^{3}$} \\
\hline \multirow[t]{2}{*}{ Sequence } & \multicolumn{2}{|c|}{ Passage 1} & \multicolumn{2}{|c|}{ Passage 2} & \multicolumn{2}{|c|}{ Passage 3} \\
\hline & Initial & Final & Initial & Final & Initial & Final \\
\hline 1) P-R-P-P-R & 15 & 60 & & 126 & & 190 \\
\hline 2) P-R-P-P-R & 23 & 73 & & 142 & & 150 \\
\hline 3) P-R-P-R & 30 & 80 & & 133 & & 140 \\
\hline 4) $P-R-R-R$ & 17 & 63 & & 80 & & 128 \\
\hline 5) P-R-R-R & 13 & 58 & & 83 & & 50 \\
\hline 6) P-R-R-R & 19 & 62 & & 82 & & 97 \\
\hline 7) P-R-R-R & 22 & 26 & & 80 & & 28 \\
\hline 8) $R-R-R-R$ & 26 & 40 & & 52 & & 68 \\
\hline
\end{tabular}

\section{Cell Morphology}

We previously reported circularity values for all-proliferative media combination P-P-P-P $(0.41 \pm 0.19$ SD), for P-R-R-R combination (sequences 4-7; $0.6 \pm 0.18 \mathrm{SD}$ ), and circularity control values of primary isolated rabbit CECs $(0.77 \pm 0.063 \mathrm{SD})[21]$. In that study, the P-P-P-P combination was discarded because it was 
detrimental for molecular expression. Our result on circularity evaluation of all-resting media combination, sequence $8 R-R-R-R$, was $0.69 \pm 0.11$ SD. Sequences 1-3 with P-R-P-R combination showed a $0.60 \pm 0.14$ SD circularity value. P-R-R-R media combination observed in Sequence 4 (Figures 1,2) was selected as the balance between circularity and a good proliferation rate. Because of that, we further evaluated roundness, aspect ratio, area and perimeter through three passages in order to assess morphological changes as shown in Figure 3.

There is a change in area and perimeter upon confluence. The observed drop in these values indicates that cell size is affected by contact inhibition.

\section{Protein Concentration, Pro-collagen I a1 Production, And $\mathrm{Na} / \mathrm{K}-\mathrm{ATP}$ ase Analysis}

Total protein concentration for CECs was $1,511.02 \pm 443.19 \mu \mathrm{g} / 1 \times 10^{5}$ and $490 \pm 70.26 \mu \mathrm{g} / 1 \times 10^{5}$ for dermal fibroblasts. Figure 4 shows the total protein concentration $\mu g$ per $1 \times 10^{5}$ cells. A significant difference with a P-value $<0.05$ was found between the CECs and control cells. Procollagen I determination showed significant difference between CECs and control cells with a P-value $<0.01$ (Figure $\mathrm{XB}$ ). Procollagen I was also found to represent less than $1 \%$ of the total protein of corneal endothelial cell lysates $(9.94 \times 10-6 \%)$ and was found to be 6 times higher compared to control cells. Na/K-ATPase concentration was $1.52 \times 10^{-6} \mathrm{U} / 10^{4}$ in CEC and $4.42 \times 10^{-7} \mathrm{U} / 10^{4}$ in HDF (Fig. 4).

\section{Biomarker Immunodetection (Z01 And ATPase)}

Whole cornea immunofluorescence showed a basal state control to compare specific marker expression and location, as well as cell morphology (Fig. 3). CECs cultured with sequence 4 expressed ZO-1 and $\mathrm{Na} / \mathrm{K}-\mathrm{ATPa}$ se. Also, ZO-1 in basal CECs and those in passage 2 showed the expected hexagonal shape and expressed the location of the protein on the apical side [16]. Nevertheless, $\mathrm{Na} / \mathrm{K}-\mathrm{ATP}$ ase basolateral location could not be assessed completely due to the swelling of stroma in whole cornea basal samples. Mitotic figures were observed at passage two; the implications will be discussed further on.

\section{Discussion}

\section{Cell yield}

All sequences showed a fold decrease with each passage as shown in Table 2. Nevertheless, sequences 4 and 6 maintained the fold number at passages 1 and 2. Also, our results on all resting media combinations RRRR (sequence 8 ) are in accordance with previous reports of low proliferation and loss of circularity within passages [19]. Moreover, days to confluence increase with each passage, regardless of 
the media combination sequence as shown in Fig. 2. This means media composition beyond the first passage is irrelevant.

Table 2

Passage fold change analysis. A fold change ratio from passage to passage was calculated to ease the comparison of cell yield within passages.

\begin{tabular}{|llll|}
\hline \multicolumn{4}{|l|}{ Passage fold change $(\boldsymbol{\Delta})$} \\
\hline Sequence & Passage 1 & Passage 2 & Passage 3 \\
\hline 1) P-R-P-P-R & 4 & 2.1 & 1.58 \\
\hline 2) P-R-P-P-R & 3.2 & 1.9 & 1.05 \\
\hline 3) P-R-P-R & 2.6 & 1.9 & 1.05 \\
\hline 4) P-R-R-R & 3.7 & 1.3 & 1.6 \\
\hline 5) P-R-R-R & 4.46 & 1.43 & 0.6 \\
\hline 6) P-R-R-R & 3.26 & 1.32 & 1.8 \\
\hline 7) P-R-R-R & 0.18 & 1.15 & 0.93 \\
\hline 8) R-R-R-R & 1.53 & 1.3 & 1.3 \\
\hline
\end{tabular}

\section{Cell Morphology}

Several authors have evaluated the effect of growth factor supplementation of culture media to harvest CECs maintaining the hexagonal morphology and molecular characteristics $[19,21,23-25]$. Our results in rabbit cells cultured in a two-phase culture system agree with the described in both, rabbit and human CECs $[17,19,26]$. Though, the main difference in the composition of our media and that of the other authors is that we do not use ROCK inhibitors. Moreover, this study has allowed us to understand that the modulation of cellular proliferation signaling produced by a two-phase culture system is only a prevention method for mesenchymal transition [21].

Shape descriptors Circularity, Roundness and Aspect Ratio tended to 1 at the end of passage 1 and 3 . This means that shape descriptors tend to hexagonallity when confluence is reached. Also, we compared obtained circularity values with previously reported results on primary isolated rabbit CECs $(0.77 \pm 0.063$ SD) and found that all PM combinations showed the lowest circularity values. On the contrary all RM combinations at sequence 8 showed the nearest circularity value. Though sequences pertaining to a two phase cultures system exhibit an intermediate value and proliferation is favored too. Thus, our two phase culture system reaches a balance between morphology and cell yield [27]. 


\section{Total Protein, Pro-collagen I And Na/K-ATPase Concentration}

Total protein, pro-collagen I, and NA/K-ATPase concentrations were higher in CECs. A heterogeneous amount of CECs per group were evaluated due to their challenging isolation and culture. Nevertheless, in all protein determinations concentration resulted to be higher on CECs. Also, normalization to single cell production was carried out for total protein and pro-collagen I in order to validate the comparison. CECs showed 3.2-fold higher protein concentration than control cells. Collagen I is one of the most abundant proteins produced by the corneal endothelium [30] whose arrangement is involved in corneal clarity. Procollagen I concentration was six times higher in CECs than in the control cells. This is in accordance with a previous study that reports CECs higher ability of proline hydroxylation than most of the fibroblastic cell lines [31]. The Na/K-ATPase colorimetric analysis for CECs is a low cost and feasible methodology that results useful to screen testing. The results support those of the immunocytochemistry analysis performed herein. Moreover, the functionality of the Na/K-ATPase is related to CECs hexagonal morphology procured with the PRRR media combination and corroborated with the morphological analyses we provide [32].

\section{Conclusions}

With the alternations of sequences of PM and RM we gathered evidence in favor of the use of dual culture media systems to improve CECs yield maintaining the hexagonal morphology. We discarded the use of pituitary extract and ROCK inhibitors as essential for CECs proliferation. Also, the PRRR sequence demonstrated to be effective and for CECs proliferation lowering the cost implied in PRPR sequences with similar results. Finally, the findings on total protein, procollagen I and $\mathrm{Na} / \mathrm{K}-\mathrm{ATP}$ ase concentrationscorroborates the immunocytochemistry evidence on cellular identity of a highly organized and active metabolic monolayer tissue.

Sketching the limits of cultured CECs expansion is an unavoidable safety issue to be addressed in order to advance onto an in-vivo model. Our study allows guaranteeing cellular and tissular quality, as well as functionality for transplantation so further efforts might focus on improving surgery practices [33] and suggesting further monitoring techniques.

\section{Declarations}

Ethics approval: This study was approved by the institutional local ethics committee (School of Medicine of Tecnologico de Monterrey), number 2019-021. All animals were treated according to the Guide for the 
Care and Use of Laboratory Animals adhering to the guidelines for the human treatment and ethical use of animals for vision research stated by the Association for Research in Vision and Ophthalmology.

Consent for publication: Not applicable.

Availability of data and materials: The datasets generated and analyzed during the current study are available from the corresponding author on reasonable request.

Competing interests: The authors declare that they have no competing interests.

Funding: Funding from Tecnologico de Monterrey and CONACYT PN 6558 was used for this project.

Authors' contributions: MPMD gathered cell yield, morphology and immunocytochemistry data; created the experimental design, analyzed data, created figures and was a major contributor in writing and reviewing the manuscript. VPIA analyzed and improved experimental design figures, and was a major contributor in writing and reviewing the manuscript. CRCE and CRIT carried out Image J morphology analysis. TGGF contributed in the gathering data for the cell yield. GED acquired Na/K ATPase data. LMM acquired protein production data. ZJ analyzed protein production and $\mathrm{Na} / \mathrm{K}$ ATPase data, created corresponding figures, was a major reviewed the manuscript and procured CONACYT funding. VGJE is the leader of our research group, performed major revisions to this manuscript and provided funding from Tecnologico de Monterrey. All authors read and approved the final manuscript.

Acknowledgements: Not applicable

\section{References}

1. Peh GSL, Toh K-P, Wu F-Y, Tan DT, Mehta JS. Cultivation of Human Corneal Endothelial Cells Isolated from Paired Donor Corneas. Mohan RR, editor. PLoS One [Internet]. 2011 [cited 2019 Nov 25];6:e28310. Available from: http://www.ncbi.nlm.nih.gov/pubmed/22194824.

2. DelMonte DW, Kim T. Anatomy and physiology of the cornea. J Cataract Refract Surg [Internet]. Elsevier; 2011 [cited 2019 Feb 25];37:588-98. Available from: http://www.ncbi.nlm.nih.gov/pubmed/21333881.

3. Brunck MEG, Nielsen LK. Concise Review: Next-Generation Cell Therapies to Prevent Infections in Neutropenic Patients. Stem Cells Transl Med [Internet]. 2014;3:541-8. Available from: https://www.ncbi.nlm.nih.gov/pubmed/26702128.

4. Vázquez N, Chacón M, Rodríguez-Barrientos CA, Merayo-Lloves J, Naveiras $M$, Baamonde $B$, et al. Human bone derived collagen for the development of an artificial corneal endothelial graft. in Vivo results in a rabbit model. PLoS One [Internet]. Public Library of Science; 2016 [cited 2019 Sep 11];11:e0167578. Available from: http://www.ncbi.nlm.nih.gov/pubmed/27907157.

5. Forest F, Thuret G, Gain P, Dumollard J-M, Peoc'h M, Perrache C, et al. Optimization of immunostaining on flat-mounted human corneas. Mol Vis [Internet]. 2015 [cited 2019 Nov 
25];21:1345-56. Available from: http://www.ncbi.nlm.nih.gov/pubmed/26788027.

6. Nakahara M, Okumura N, Kay EP, Hagiya M, Imagawa K, Hosoda Y, et al Corneal Endothelial Expansion Promoted by Human Bone Marrow Mesenchymal Stem Cell-Derived Conditioned Medium. Covas DT, editor. PLoS One [Internet]. 2013 [cited 2019 Nov 25];8:e69009. Available from: http://www.ncbi.nlm.nih.gov/pubmed/23894393.

7. Bukowiecki A, Hos D, Cursiefen C, Eming SA. Wound-Healing Studies in Cornea and Skin: Parallels, Differences and Opportunities. Int J Mol Sci [Internet]. Multidisciplinary Digital Publishing Institute (MDPI); 2017 [cited 2019 Feb 25];18. Available from: http://www.ncbi.nlm.nih.gov/pubmed/28604651.

8. Bourne WM. Biology of the corneal endothelium in health and disease. Eye. 2003;17:912-8.

9. Whitcher JP, Srinivasan M, Upadhyay MP. Corneal blindness: A global perspective. Bull World Health Organ. 2001;79:214-21.

10. Wong KH, Kam KW, Chen LJ, Young AL. Corneal blindness and current major treatment concern-graft scarcity. Int J Ophthalmol [Internet]. International Journal of Ophthalmology Press; 2017;10:115462. Available from: http://www.ncbi.nlm.nih.gov/pmc/articles/PMC5514281/.

11. $10.1038 /$ eye. 2013.15

Zavala J, López Jaime GR, Rodríguez Barrientos CA, Valdez-Garcia J. Corneal endothelium: developmental strategies for regeneration. Eye [Internet]. 2013;27:579-88. Available from: http://www.nature.com/doifinder/10.1038/eye.2013.15.

12. Bartakova A, Alvarez-Delfin K, Weisman AD, Salero E, Raffa GA, Merkhofer RM, et al. Novel Identity and Functional Markers for Human Corneal Endothelial Cells. Investig Opthalmology Vis Sci [Internet]. 2016;57:2749. Available from: http://iovs.arvojournals.org/article.aspx? doi=10.1167/iovs.15-18826.

13. Peh GSL, Toh K, Wu F, Tan DT, Mehta JS. Cultivation of Human Corneal Endothelial Cells Isolated from Paired Donor Corneas. Mohan RR, editor. PLoS One [Internet]. 2011;6:e28310. Available from: http://journals.plos.org/plosone/article?id=10.1371/journal. pone.0028310.

14. Zhu C, Joyce NC. Proliferative Response of Corneal Endothelial Cells from Young and Older Donors. Investig Opthalmology Vis Sci [Internet]. 2004 [cited 2019 Nov 25];45:1743. Available from: http://www.ncbi.nlm.nih.gov/pubmed/15161835.

15. http://dx.plos.10.1371/journal.pone.0042378 Ju C, Zhang K, Wu X. Derivation of Corneal Endothelial Cell-Like Cells from Rat Neural Crest Cells In Vitro. Asakura A, editor. PLoS One [Internet]. 2012;7:e42378. Available from: http://dx.plos.org/10.1371/journal.pone.0042378.

16. Zhao JJ, Afshari NA. Generation of Human Corneal Endothelial Cells via In Vitro Ocular Lineage Restriction of Pluripotent Stem Cells. Investig Opthalmology Vis Sci [Internet]. 2016;57:6878. Available from: http://iovs.arvojournals.org/article.aspx?doi=10.1167/iovs.16-20024.

17. Peh GS, Toh K-P, Ang H-P, Seah X-Y, George BL, Mehta JS. Optimization of human corneal endothelial cell culture: density dependency of successful cultures in vitro. BMC Res Notes [Internet]. 2013 [cited 
2019 Nov 25];6:176. Available from: http://www.ncbi.nlm.nih.gov/pubmed/23641909.

18. Okumura N, Matsumoto D, Fukui Y, Teramoto M, Imai H, Kurosawa T, et al. Feasibility of cell-based therapy combined with descemetorhexis for treating Fuchs endothelial corneal dystrophy in rabbit model. PLoS One. 2018;13:1-14.

19. $10.3727 / 096368913 \times 675719$

Peh GSL, Chng Z, Ang HP, Cheng TYD, Adnan K, Seah XY, et al. Propagation of human corneal endothelial cells: A novel dual media approach. Cell Transplant [Internet]. SAGE PublicationsSage CA: Los Angeles, CA; 2015 [cited 2019 Jan 31];24:287-304. Available from: http://journals.sagepub.com/doi/full/10.3727/096368913X675719.

20. Kim E, Kim JJ, Hyon JY, Chung E-S, Chung T-Y, Yi K, et al. The Effects of Different Culture Media on Human Corneal Endothelial Cells. Investig Opthalmology Vis Sci [Internet]. 2014 [cited 2019 Nov 25];55:5099. Available from: http://www.ncbi.nlm.nih.gov/pubmed/25034603.

21. Rodríguez-Barrientos C-A, Trevino V, Zavala J, Montalvo-Parra M-D, Guerrero-Ramírez G-I, AguirreGamboa R, et al. Arresting proliferation improves the cell identity of corneal endothelial cells in the New Zealand rabbit. Mol Vis [Internet]. Emory University; 2019 [cited 2020 Mar 31];25:745-55. Available from: http://www.ncbi.nlm.nih.gov/pubmed/31814700.

22. HAI Laboratories I. Visual Atlas of Eye Bank Specular Microscopy - Donor Corneal Endothelium Imaging [Internet]. 2013. p. 1-17. Available from: http://hailabs.com/wpcontent/uploads/2014/05/Visual-Atlas-of-Eye-Bank-Specular-Microscopy.pdf.

23. Joyce NC, Zhu CC. Human corneal endothelial cell proliferation: potential for use in regenerative medicine. Cornea [Internet]. 2004 [cited 2019 Mar 4];23:S8-19. Available from: http://www.ncbi.nIm.nih.gov/pubmed/15448474.

24. Bartakova A, Kuzmenko O, Alvarez-Delfin K, Kunzevitzky, Noelia J, Goldberg J. A Cell Culture Approach to Optimized Human Corneal Endothelial Cell Function. Cornea. 2018;59:1617-29.

25. Noh JW, Kim JJ, Hyon JY, Chung ES, Chung TY, Yi K, et al. Stemness characteristics of human corneal endothelial cells cultured in various media. Eye Contact Lens [Internet]. 2015 [cited 2019 Nov 25];41:190-6. Available from: http://www.ncbi.nlm.nih.gov/pubmed/25603434.

26. Peh GSL, Ang H-P, Lwin CN, Adnan K, George BL, Seah X-Y, et al. Regulatory Compliant TissueEngineered Human Corneal Endothelial Grafts Restore Corneal Function of Rabbits with Bullous Keratopathy. Sci Rep [Internet]. Nature Publishing Group; 2017 [cited 2019 Oct 29];7:14149. Available from: http://www.nature.com/articles/s41598-017-14723-z.

27. Montalvo MD, Zavala J. Evaluation of cultured corneal endothelial cells morphology with an easy and free tool. Invest Ophthalmol Vis Sci. 2018;59:1376.

28. Vázquez N, Rodríguez-Barrientos CA, Aznar-Cervantes SD, Chacón M, Cenis JL, Riestra AC, et al. Silk Fibroin Films for Corneal Endothelial Regeneration: Transplant in a Rabbit Descemet Membrane Endothelial Keratoplasty. Investig Opthalmology Vis Sci [Internet]. 2017 [cited 2019 Nov 27];58:3357. Available from: http://www.ncbi.nlm.nih.gov/pubmed/28687847.

29. http://doi.wiley.com/10.1002/jcp.1041070203

Page 12/18 
Gospodarowicz D, Greenburg G, Foidart JM, Savion N. The production and localization of laminin in cultured vascular and corneal endothelial cells. J Cell Physiol [Internet]. John Wiley \& Sons, Ltd; 1981 [cited 2020 Apr 18];107:171-83. Available from: http://doi.wiley.com/10.1002/jcp.1041070203.

30. Dyrlund TF, Poulsen ET, Scavenius C, Nikolajsen CL, Thøgersen IB, Vorum H, et al. Human cornea proteome: Identification and quantitation of the proteins of the three main layers including epithelium, stroma, and endothelium. J Proteome Res American Chemical Society. 2012;11:4231-9.

31. Perlman M, Baum JL, Kaye GI. Fine structure and collagen synthesis activity of monolayer cultures of rabbit corneal endothelium. J Cell Biol [Internet]. 1974 [cited 2020 Apr 18];63:306-11. Available from: http://www.ncbi.nlm.nih.gov/pubmed/4472479.

32. He Z, Forest F, Gain P, Rageade D, Bernard A, Acquart S, et al. 3D map of the human corneal endothelial cell. Sci Rep [Internet]. Nature Publishing Group; 2016 [cited 2019 Sep 6];6:29047. Available from: http://www.nature.com/articles/srep29047.

33. Javadi M, Feizi S, Jafari R, Hosseini S, Safapour S. Factors influencing graft endothelial cell density after descemet stripping automated endothelial keratoplasty. J Ophthalmic Vis Res [Internet]. 2018;13:10. Available from: http://www.jovr.org/text.asp?2018/13/1/10/222909.

\section{Figures}




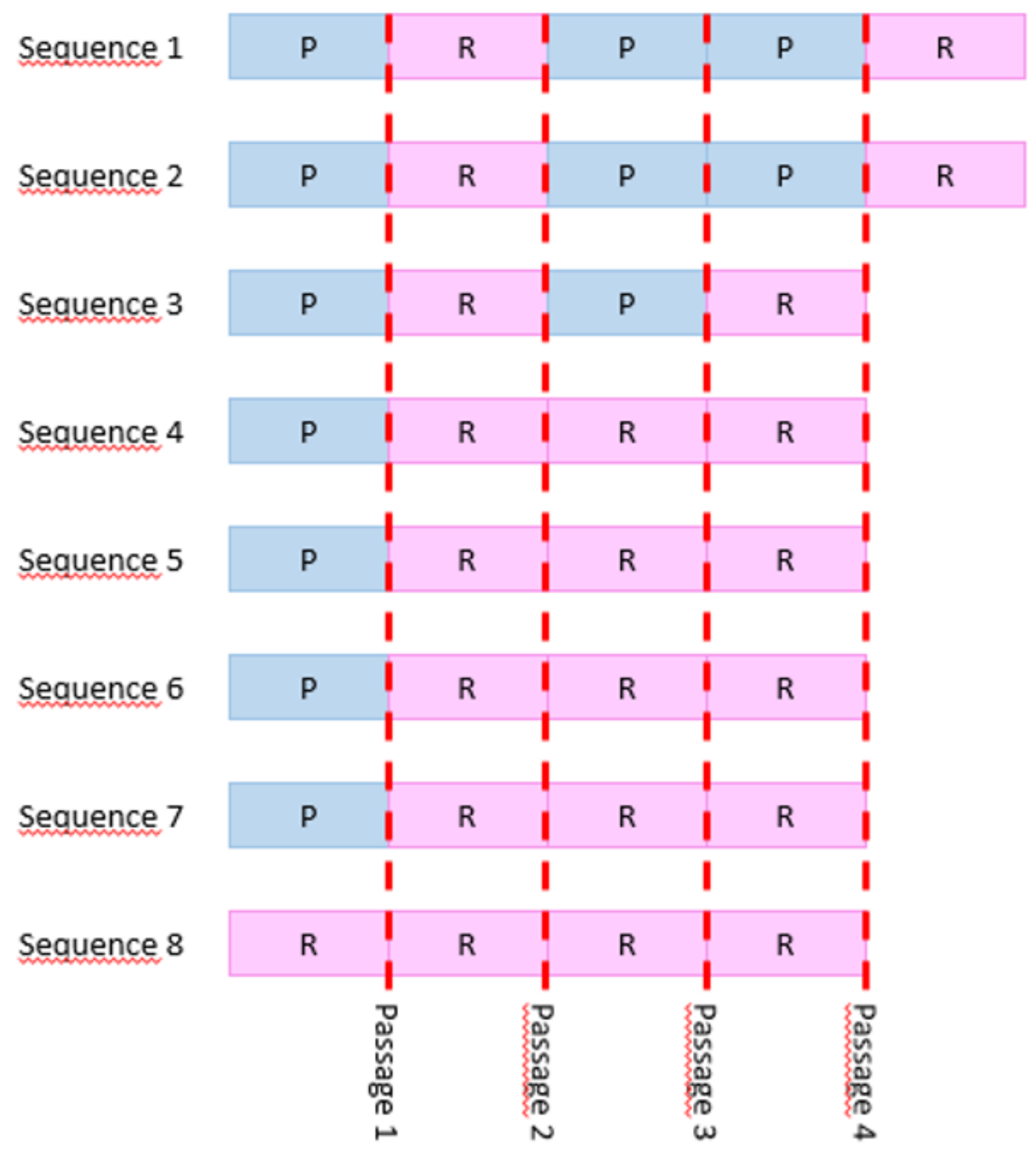

Figure 1

Experimental design. Eight sequences of alternating proliferative $(P)$ and resting $(R)$ were evaluated. All cultures were stabilized with proliferative media until confluence at passage 0 ; sequence 8 was the exception. Passages are marked with dashed red lines. 


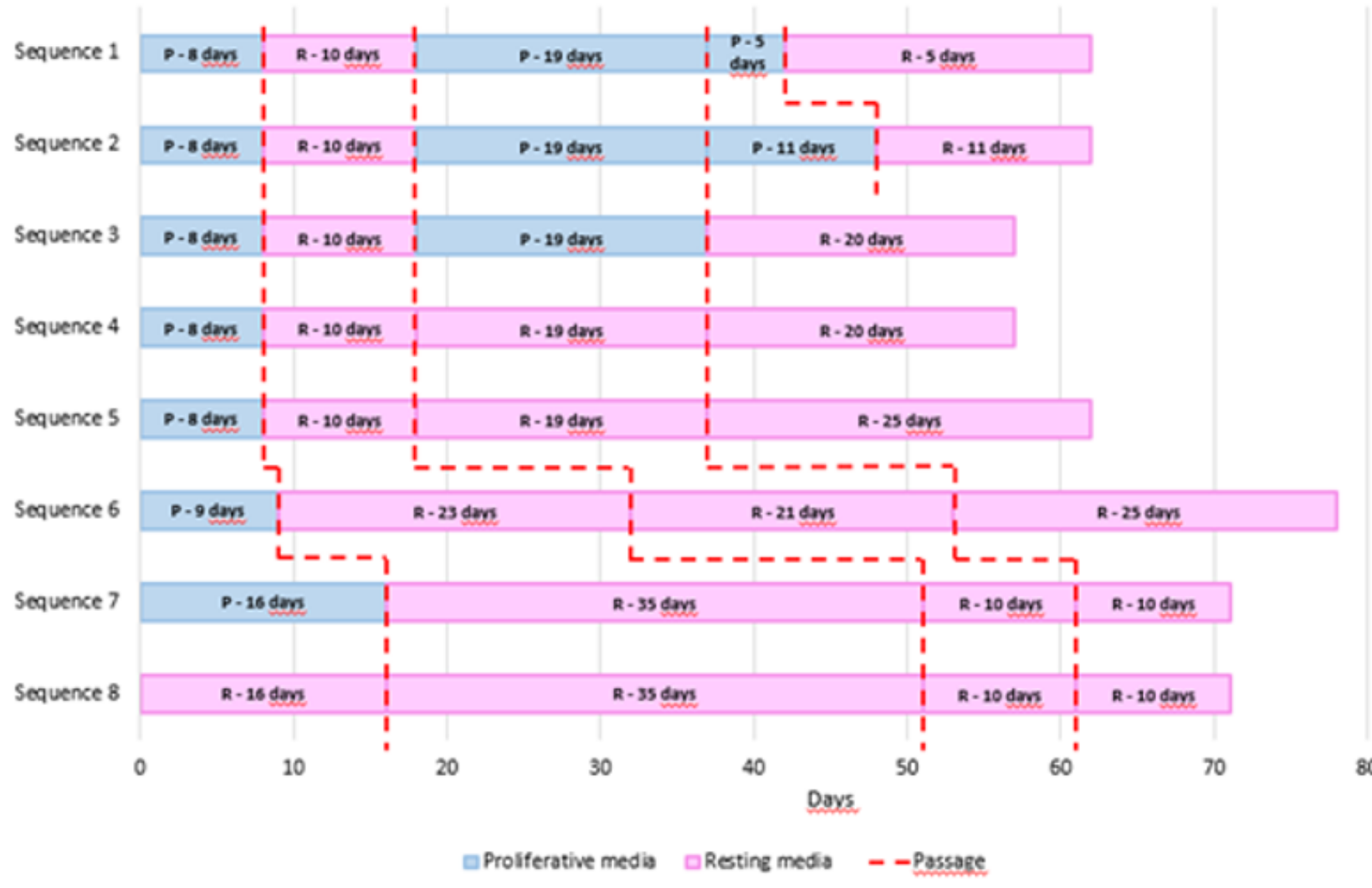

\section{Figure 3}

Media alternation sequence design. The first approach to optimum media sequence was determined through this experimental design. Passage number was totally experimental as in a screening study to corroborate literature. Proliferative media $(\mathrm{P})$; resting media $(\mathrm{R})$. 
(a)

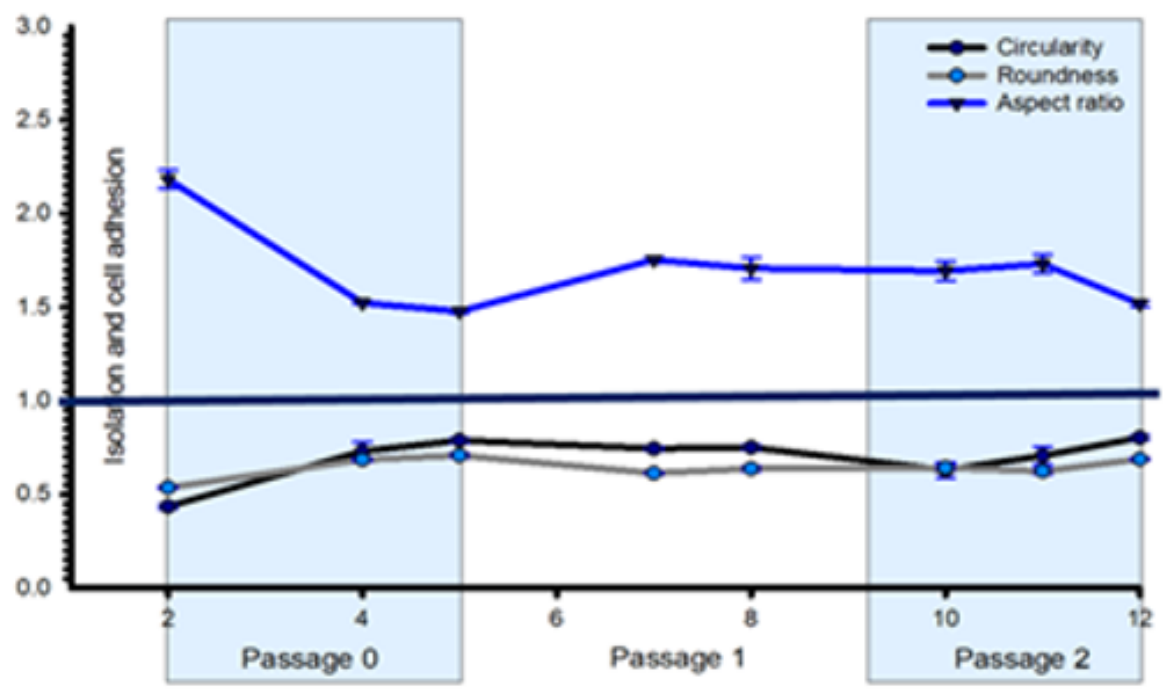

(b)

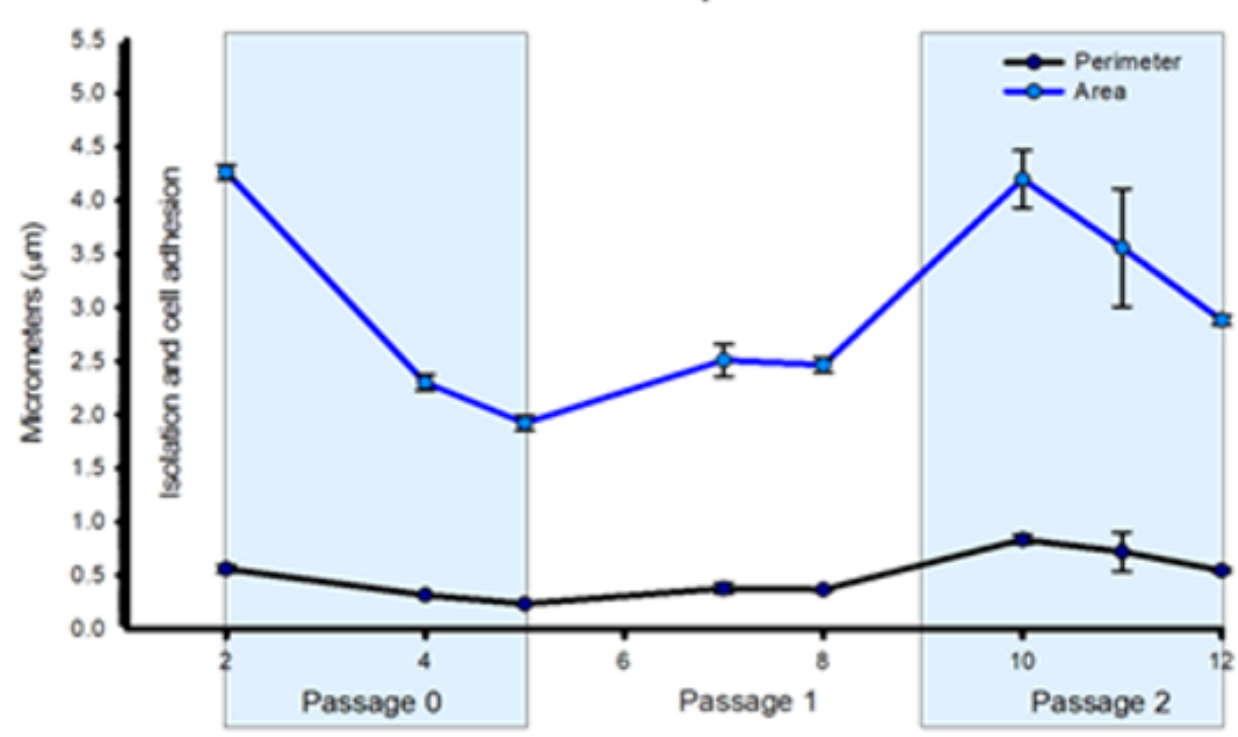

Culture days (c)

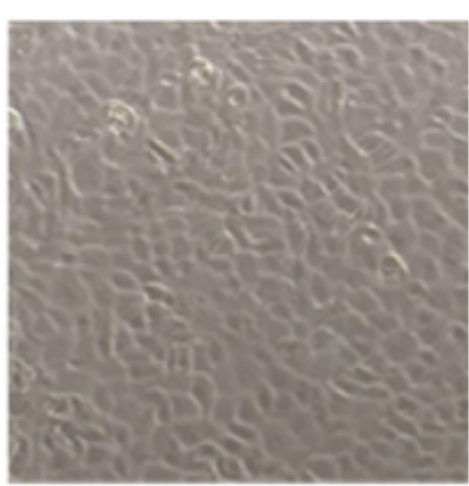

(d)

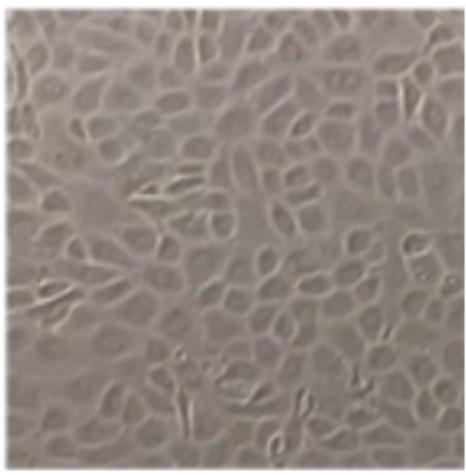

(e)

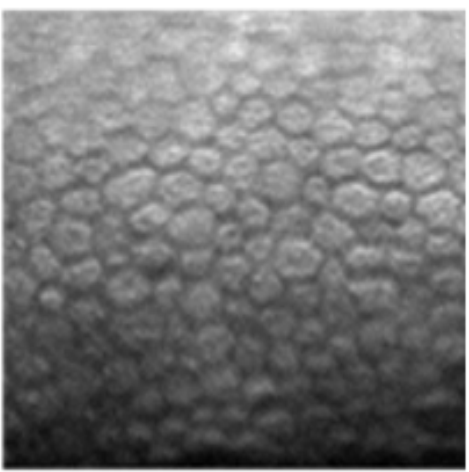

Figure 5

Culture of rabbit corneal endothelium cells with a PRR combination. a) Changes in shape descriptors: circularity, roundness and aspect ratio; b) changes in cell area and perimeter; c) rabbit corneal endothelium cells at passage 0 , day 3 ; d) rabbit corneal endothelium cells at passage 2; e) human corneal endothelium from the Visual Atlas of Eye Bank Specular Microscopy - Donor Corneal Endothelium Imaging [22]. 

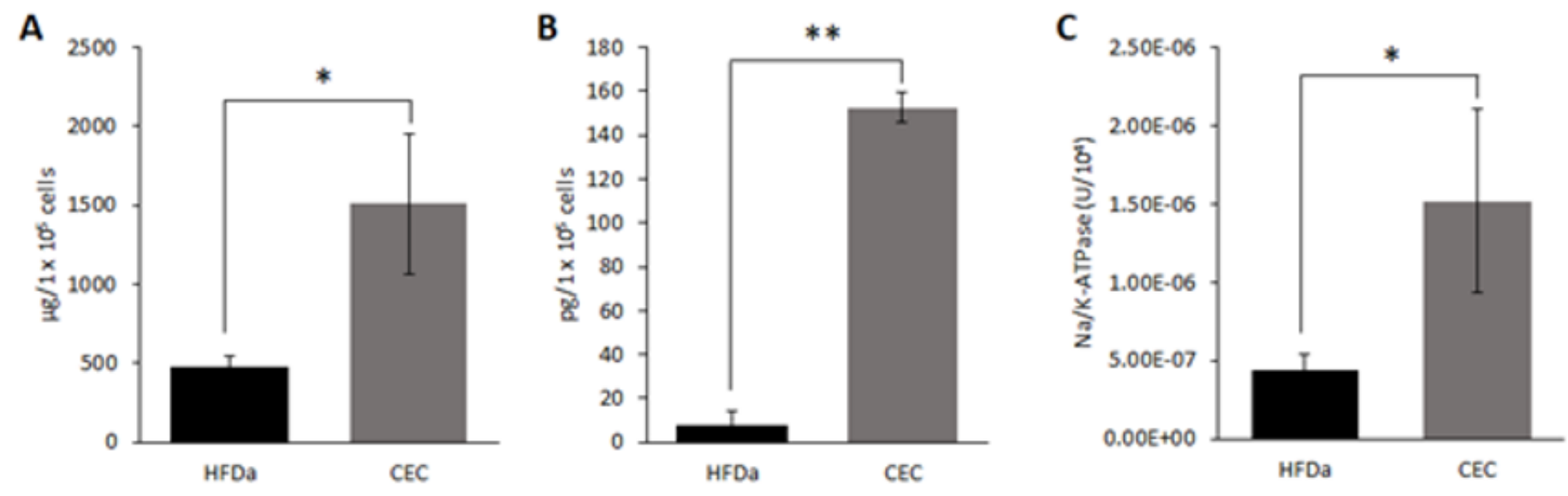

Figure 7

Protein production analysis. Total protein concentration a), pro-collagen I b), and Na/K-ATPase c) in HDFA and CECs cultured with the media sequence 4 PRRR. $\left({ }^{*} p<0.05,{ }^{*} p<0.01\right)$.

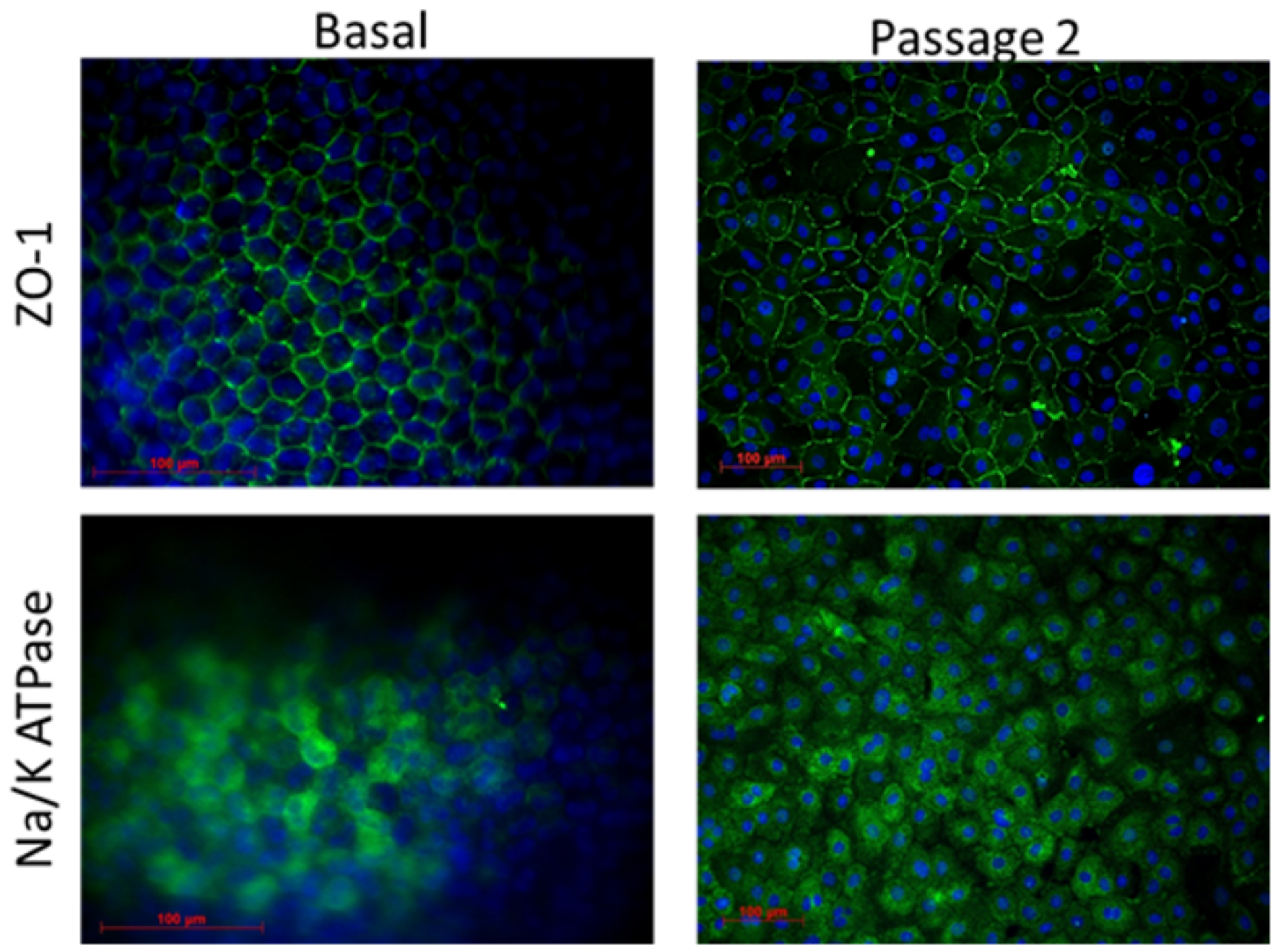

Figure 9 
Immunocytochemistry of specific molecular markers of basal and cultured rabbit corneal endothelium cells. Basal corneal endothelium epifluorescence images of a whole cornea exhibit Zonula Occludens tight junctions (ZO-1) and Sodium-Potassium ATPase (Na/K-ATPase) expression. Also, cultured corneal endothelium cells exhibit the specific molecular markers. 